\title{
Smoking cessation intervention among Vietnamese Americans: a controlled trial
}

\author{
Stephen J McPhee, Christopher NH Jenkins, Ching Wong, Don Fordham,
} Ky Quoc Lai, Joyce Adair Bird, Joel M Moskowitz

\begin{abstract}
Objective - To evaluate the effectiveness of a culturally appropriate, media-led information and education smoking cessation campaign.

Design-Two-year controlled trial, multicomponent programme.

Subjects and setting - Vietnamese men living in Santa Clara County, California, US.

Main outcome measures - Pretest (1990) and post-test (1992) surveys of randomly selected Vietnamese men in Santa Clara County and Houston, Texas, serving as a comparison community.

Results-In both 1990 and 1992, adult males in both communities were more likely to smoke if they were younger ( $p<$ $0.005)$, if they were more recent immigrants $(p<0.001)$, if they had less than a high school education $(p<0.005)$, or if their English proficiency was limited (p $<0.001$ ). Between 1990 and 1992, smoking prevalence remained constant in Santa Clara County (36\% in $1990 ; 36 \%$ in 1992$)$, and in Houston $(40 \%$ in $1990 ; 41 \%$ in 1992). The proportions of recent quitters, although greater in Santa Clara County than Houston, did not change significantly between pretest and post-test in either community.

Conclusion - The continuing high smoking prevalence rate among Vietnamese men in Santa Clara County suggests a need for continuing intervention, particularly among recent immigrants.
\end{abstract}

(Tobacco Control 1995; 4 (suppl 1): S16-S24)

Keywords: cessation; intervention; Vietnamese Americans

\section{Introduction}

Over 615000 Vietnamese live in the US. ${ }^{1}$ California's 280000 Vietnamese represent nearly half $(46 \%)$ of all Vietnamese in the country. One in every hundred Californians is Vietnamese. The Vietnamese are almost entirely first-generation immigrants who arrived in the US in the years following the fall of the Saigon regime in 1975. Most Vietnamese $(83 \%)$ speak Vietnamese at home. ${ }^{1}$ Vietnamese are the fastest growing Asian/Pacific Islander ethnic group in the US. By the year 2030, demographers predict that they will constitute the second largest Asian/Pacific Islander ethnic group in the US and that their numbers will reach nearly 4 million. ${ }^{2}$

Cigarette smoking poses a major health hazard for Vietnamese men. In California, $35 \%$ of Vietnamese men smoke cigarettes compared with $27.5 \%$ of men in the general US population). ${ }^{3-5}$ In contrast, fewer than $1 \%$ of Vietnamese women in California smoke cigarettes (compared with $23.6 \%$ of women in the general US population). Vietnamese men, therefore, have a high risk of developing tobacco-related diseases, such as cancer, heart disease, and chronic lung disease.

In earlier studies, we learned that $25 \%$ of Vietnamese did not know that cancer was related to smoking. Vietnamese men were more likely to be smokers if they were ignorant of the smoking-cancer relationship, if they had incomes below the poverty level, if they were more recent immigrants, and if they had limited proficiency in the English language. ${ }^{6}$

In 1988, voters in California passed the Tobacco Tax and Health Promotion Act (Proposition 99), which mandated an increase of 25 cents per pack in the cigarette excise tax on 1 January 1989 and required that a portion of these tax revenues be used for tobacco prevention and control activities in schools and communities. Beginning in the Spring of 1990, the State of California mounted a vigorous tobacco education campaign (predominantly in English and Spanish). ${ }^{7,8}$ At the same time, local communities and advocacy organisations succeeded in passing a growing number of smoking control ordinances to restrict smoking in public places and at worksites throughout the state.

As no culturally appropriate smoking cessation interventions existed for the Vietnamese, starting in July 1989 we implemented a 15month pilot anti-tobacco media programme in the San Francisco Bay area. Based on the experience gained from this pilot programme, between November 1990 and October 1992 we mounted a media-led information and education campaign, which we evaluated in a controlled trial. The campaign targeted male Vietnamese living in Santa Clara County, California, an area 50 miles south of San Francisco, and who had recently immigrated. Houston, Texas was selected as the comparison community. This paper reports an evaluation of the effectiveness of this intervention. 


\section{Methods}

\section{INTERVENTION}

Starting in 1990, we prepared a series of 35 feature newspaper articles about the health hazards of smoking, each of which was published in up to 10 different Vietnamese language newspapers and magazines, resulting in 83 printings and 562000 print media exposures. For the electronic media, we produced a 22 minute videotape in Vietnamese, which featured interviews with Vietnamese male smokers about their reasons for smoking, interviews with Vietnamese community physicians about the health hazards of smoking, and finally, interviews with Vietnamese male quitters about how they quit and how they refused cigarettes when offered. The videotape was broadcast twice on Vietnamese language television during a weekday dinner hour. In addition, copies of the videotape were distributed to more than 60 Vietnamese doctors' offices and 20 community agencies in Santa Clara County.

Using focus groups, we produced Vietnamese language health education materials, including three posters, a calendar, bumper stickers, lapel badges, and two brochures. One brochure targeted male smokers and described the health hazards of smoking and the benefits of quitting. The second brochure targeted females and described the health effects of environmental tobacco smoke on children and family members. Nearly 42000 copies of the brochures were distributed at over 500 locations in Santa Clara County. We also produced a 32-page, four-colour, self-help "quit kit" that targeted those who wanted advice on how to stop smoking. Nearly 6000 copies of the kit were distributed at more than 250 locations. Project staff re-supplied community businesses and agencies with brochures and kits throughout the intervention period.

We launched an outdoor, print and electronic media counter-advertising campaign. For outdoor media, we developed Vietnamese language billboards of three different types which were posted in neighbourhoods with high concentrations of Vietnamese. One billboard targeted cigarette offering behaviour, the second focused on refusal skills, and the third billboard modelled quitting behaviour in a family context. The billboard targeting the offering of cigarettes was the first billboard ever to appear in the Vietnamese language in the US and drew considerable print and electronic media attention when it was first posted. ${ }^{9-11}$ Overall, 50 copies of the three billboards were posted each for one month. We adapted each billboard image into print advertisements, which were printed regularly in 18 weekly and daily newspapers and magazines 1196 times resulting in nearly 8000000 print media exposures. Six paid anti-tobacco television advertisements, based on segments of the videotape, were broadcast regularly on Vietnamese language television during an early evening time slot, accounting for nearly 13000 seconds of air time.

Project staff gave short anti-tobacco presentations at 30 community events and adapted the American Cancer Society's Great American Smokeout programme for the Vietnamese population in 1990 and 1991.

We organised a Continuing Medical Education course on smoking cessation counselling methods for 68 Vietnamese physicians, members of a regional Vietnamese physicians' professional association in Santa Clara County. Each physician was given copies of the project's self-help kit for use in counselling, and copies of the videotape, posters, and brochures with holders for waiting room display. Project staff re-supplied physicians with educational materials throughout the intervention period.

Finally, to promote smoke-free environments in the Vietnamese community, we translated smoking control ordinances in Santa Clara County into Vietnamese, and printed and distributed them to Vietnamese businesses and restaurants. We also printed and distributed 1140 signs with adhesive backings saying "Please do not smoke" in Vietnamese, to help in establishing non-smoking areas in public places.

\section{DESIGN EVALUATION}

In planning our study, we put forward two hypotheses: that the reduction in smoking prevalence following the intervention in the experimental community would be significantly greater than in the comparison community; and that the proportion of smokers who quit during the intervention period would be significantly greater in the experimental than in the comparison community.

Santa Clara County was selected as the intervention site both because of its large population of Vietnamese and its proximity to the investigators. The 1990 Census data show that Santa Clara County is home to $\mathbf{5 4 2 1 2}$ Vietnamese, of whom 18770 are males aged 18 or older. ${ }^{1}$ Most reside in the city of San Jose.

Houston was chosen as the comparison site because it is the area with the highest concentration of Vietnamese outside California. The 1990 Census data show that the primary metropolitan statistical area of Houston is home to 33035 Vietnamese, of whom 11878 are males aged 18 or older. ${ }^{1}$ We chose a comparison site outside California to reduce the possibility of subjects being influenced by other anti-tobacco interventions funded by California Proposition 99. In addition, an increase in the excise tax on cigarettes by 15 cents per pack in Texas on 1 September 1989 made Texas a more equivalent comparison community than other potential sites without recent tax increases (personal communication, Steven Tobias, Office of Smoking and Health, Texas Department of Health, 12 March 1993). In both Santa Clara County and Houston, there were local ordinances placing restrictions on smoking in workplaces, restaurants, and retail stores throughout the study period. ${ }^{12}$

Survey subjects were required to be male, aged 18 or older, and Vietnamese speaking (as all intervention activities were conducted in 
the Vietnamese language). Vietnamese women were excluded from the study because of the negligible prevalence of smoking. ${ }^{3,4,6,13}$

The study used an untreated control group design with separate pretest and post-test samples. ${ }^{14}$ Pretest measurements were made in both intervention and comparison sites in September-October 1990. Intervention activities were conducted in Santa Clara County between November 1990 and October 1992. Post-test measurements were repeated in intervention and comparison sites in November and December 1992

We conducted telephone surveys of randomly selected Vietnamese men in Santa Clara County and in Houston, Texas. Telephone numbers were chosen randomly from the 23 most common Vietnamese surnames listed in area telephone books. After enumerating all men aged 18 or older who lived in the household and who understood Vietnamese, survey workers selected a subject for interview according to a modified Kish procedure. ${ }^{15}$ Anticipating a baseline smoking prevalence rate of $45 \%$ among Vietnamese males, we performed a power calculation to determine the sample size needed to detect a 5\% reduction in smoking prevalence with $\alpha=0.05$ and $\beta=0.80$. Based on this calculation, we set a goal of at least 1200 interviews in each community. The research protocol was approved by the Committee on Human Research at the University of California, San Francisco.

\section{MEASURES}

The survey instrument was developed in English, translated into Vietnamese and backtranslated into English to ensure lexical equivalency, and then pilot-tested. All interviews were conducted in Vietnamese. Subjects were asked if they had ever smoked cigarettes and if, during the previous week, they had smoked a cigarette. Respondents were classified as current smokers if they responded "yes" to both questions, as former smokers if they responded "yes" to the first and "no" to the second question, and as never-smokers if they responded "no" to the first question. Current smokers were asked how many cigarettes on average they smoked per day, and how many years they had smoked. To measure motivation to quit, current smokers were asked how much they wanted to quit smoking. To measure levels of quitting self-efficacy, current smokers were asked how difficult they thought it would be to quit smoking, and if they had ever tried to quit smoking (and, if so, on how many occasions). Former smokers were asked how long ago they had quit smoking.

To measure changes in social norms regarding smoking, we asked respondents how many of their friends smoked and if members of their household smoked. In addition, we asked never-smokers and former smokers if they had ever advised a family member or friend to quit; we asked smokers and former smokers if they had ever been advised by a family member or friend to quit. To assess the effectiveness of the physician education com- ponent, we asked respondents if their physician had ever advised them to quit smoking.

Exposure to intervention activities was assessed by asking all subjects if they had ever read an article or seen an advertisement in a Vietnamese language newspaper, or seen a television programme or billboard in Vietnamese, or heard a speech at a Vietnamese community meeting about the hazards of smoking or the benefits of quitting. Those who reported seeing a billboard were asked to describe the visual image or written copy of any of the three billboards.

Demographic data collected included respondent age, year of immigration to the US, highest level of education, English language proficiency, employment status, and poverty status. Poverty status, based on household size, was determined using criteria established by the US Department of Health and Human Services. ${ }^{16,17}$

\section{DATA ANALYSIS}

To assess change in prevalence of cigarette smoking over the two-year study interval, we examined two outcomes: the proportion of current smokers; and the proportion of former smokers who were recent quitters. "Recent quitters" were defined as those who had quit smoking during the two years before either the pretest or post-test interview. Analyses focused on describing differences in outcomes between experimental and comparison subjects at pretest and post-test. In preliminary analyses of sociodemographic characteristics and smoking behaviours, we used $t$ tests to test the significance of differences in means, and $\chi^{2}$ tests to test the significance of differences in proportions.

To control simultaneously for any differences in sociodemographic factors that might have accounted for differences in smoking behaviours, we performed multiple logistic regression analyses. Covariates were selected by examining cross-tabulations of the demographic independent variables with each dependent variable for each of the four conditions. Multiple logistic regression models were computed separately on the four samples and on the pooled data. The regressions were performed to identify variables significantly associated with non-smoking status and recent quitting status, the major dependent variables. The analyses used three dummy variables: time ( $0=$ pretest, $1=$ post-test) to assess secular trends across sites; site $(0=$ comparison, 1 $=$ intervention) to assess site differences across time; and time $\times$ site, the intervention term, ( 1 $=$ intervention site at post-test, $0=$ all other conditions) to assess the intervention effect. Adjusted odds ratios (ORs) in the multivariate analyses were computed for different covariates with $95 \%$ confidence intervals (CIs). Analyses were performed using the LOGISTIC procedure in the SAS statistical package. ${ }^{18}$

\section{Results}

Response rates were similar for intervention 
Table 1 Demographic characteristics of respondents to pretest and post-test telephone surveys in comparison $(H O U)$ and experimental (SCC) communities

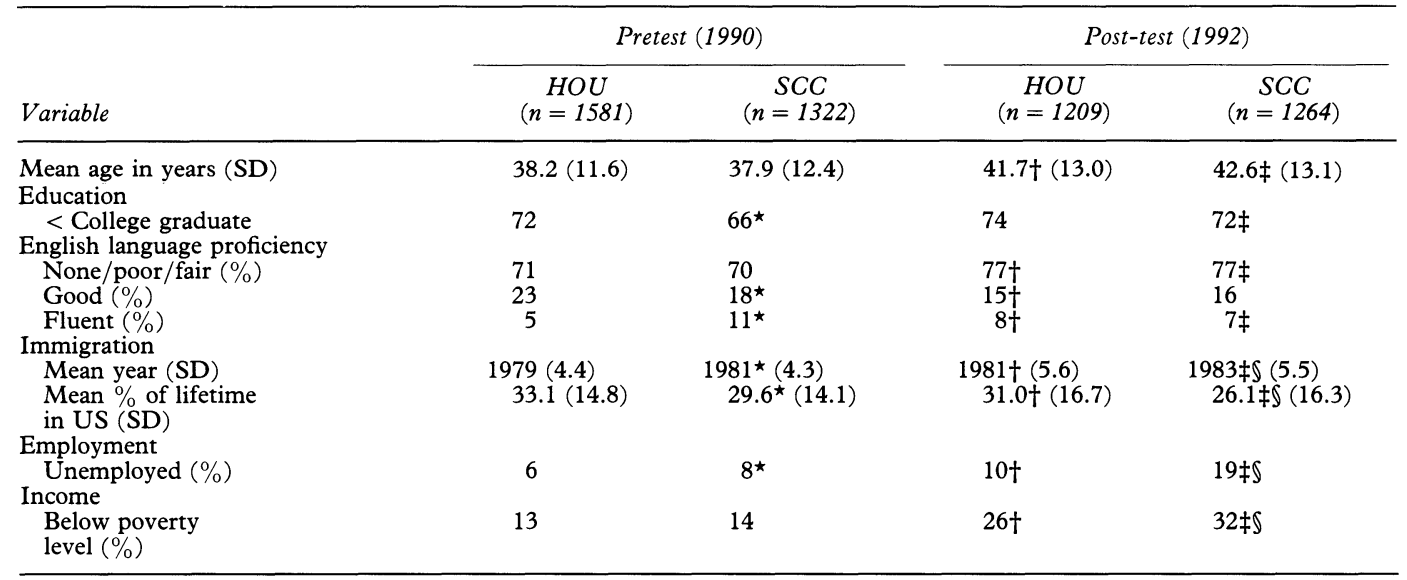

$\star \mathrm{p}<0.05$, comparison of pretest HOU and pretest SCC.

$+\mathrm{p}<0.05$, comparison of pretest HOU and post-test HOU.

$\mathrm{p}<0.05$, comparison of pretest SCC and post-test SCC.

f $\mathrm{p}<0.05$, comparison of post-test HOU and post-test SCC

and comparison communities $(81 \%$ in Santa Clara County vs $82 \%$ in Houston, pretest; $85 \%$ in Santa Clara County vs $88 \%$ in Houston, post-test). (In calculating response rates, we excluded call attempts which reached businesses, households with no eligible males, disconnected telephones, answering machines, and telephones with no answer after five callback attempts at different times of day.)

\section{SOCIODEMOGRAPHIC CHARACTERISTICS OF} SURVEY RESPONDENTS

Table 1 shows the sociodemographic characteristics of respondents. Although there were significant differences among the four samples for mean age, educational level, English language proficiency, and mean year of immigration, these differences were small in magnitude. More substantial differences were found for employment and income. In the multivariate analyses, we controlled for the differences in all of these variables differences.

\section{EXPOSURE TO INTERVENTION ACTIVITIES}

The data in figure 1 show the differences at post-test between Santa Clara County and Houston in respondents' reported exposure to anti-smoking activities in the Vietnamese

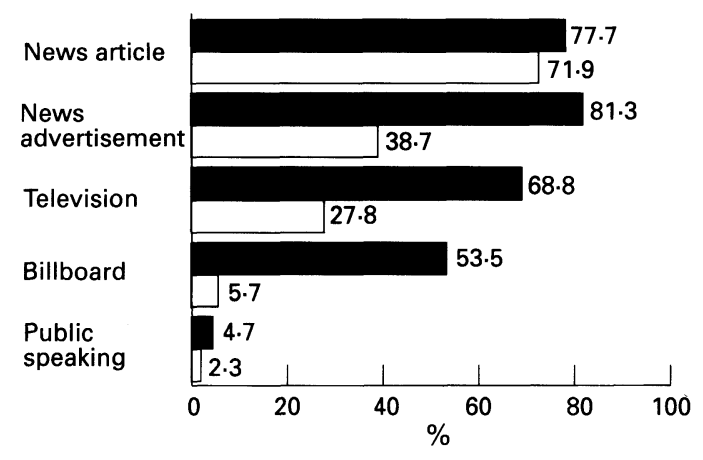

Figure 1 Exposure to intervention elements among respondents in experimental and comparison communities at post-test survey. Santa Clara (solid bars, $n=1264$ ) vs Houston (open bars, $n=1209$ ). language. All differences are statistically significant at the $p<0.05$ level except for newspaper articles and public speaking.

Smokers in Santa Clara County recalled a mean of 3.0 intervention elements out of the possible total of five intervention elements, whereas Houston smokers reported exposure to a mean of only 1.6 intervention elements ( $p$ $<0.01$ ). Non-smokers in Santa Clara County recalled 2.8 elements whereas Houston nonsmokers reported exposure to a mean of 1.4 elements $(\mathrm{p}<0.01)$.

Compared with pretest, significantly more Santa Clara County Vietnamese physicians reported at post-test using anti-smoking brochures in the Vietnamese language $(86.4 \%$ vs $\left.32.5 \%, \chi^{2} \mathrm{p}=0.001\right)$, providing self-help "quit kits" (66.7\% vs $43.2 \%, p=0.03)$, and referring patients to smoking cessation programmes $(35.9 \%$ vs $13.5 \%, p=0.02)$. At post-test, $96.4 \%$ of the physicians reported that the Vietnamese health education materials were helpful.

\section{SMOKING BEHAVIOURS}

Table 2 shows that, at pretest, the smoking prevalence rate was $36 \%$ in Santa Clara County; this was significantly lower than the $40 \%$ rate in Houston. Between pretest and post-test, smoking prevalence remained stable in Santa Clara County and in Houston. As shown, the proportion of recent quitters, although greater in Santa Clara County than in Houston, did not change significantly between pretest and post-test in either community.

At pretest and post-test, adult males in each community were more likely to smoke if they were younger $(\mathrm{p}<0.005)$, if they were more recent immigrants $(p<0.001)$, if they had less than a high school education $(p<0.005)$, or if their English proficiency was limited $(\mathrm{p}<$ 0.001 ).

Table 2 also shows that current smokers in Santa Clara County smoked significantly fewer cigarettes per day than those in Houston, both at pretest and at post-test. At pretest, smokers in Santa Clara County were more motivated to 
Table 2 Smoking behaviors of respondents to pretest and post-test telephone surveys in comparison (HOU) and experimental (SCC) communities

\begin{tabular}{|c|c|c|c|c|}
\hline \multirow[b]{2}{*}{ Variable } & \multicolumn{2}{|c|}{ Pretest (1990) } & \multicolumn{2}{|c|}{ Pre-test (1992) } \\
\hline & $H O U$ & $S C C$ & $H O U$ & $S C C$ \\
\hline $\begin{array}{l}\text { Among all respondents } \\
\text { Current smokers }(\%) \\
\text { Former smokers }(\%) \\
\text { Recent quitters }(\%) \\
\text { Household member smokes (\%) } \\
\text { All/most friends smoke }(\%) \\
\text { No friends smoke }(\%)\end{array}$ & $\begin{array}{l}(\mathrm{n}=1581) \\
40 \\
14 \\
6 \\
29 \\
46 \\
3\end{array}$ & $\begin{array}{l}(\mathrm{n}=1322) \\
36 \dagger \\
20 \\
8 \dagger \\
31 \\
48 \\
4\end{array}$ & $\begin{array}{l}41^{(\mathrm{n}=1209)} \\
22 \\
7 \\
24 \ddagger \\
51 \ddagger \\
13 \ddagger\end{array}$ & $\begin{array}{l}\quad(\mathrm{n}=1264) \\
36 \| \\
24 \\
10 \| \\
26 \$ \\
44 \| \\
15 \$\end{array}$ \\
\hline $\begin{array}{l}\text { Among current smokers } \\
\text { Mean number cigarettes/day (SD) } \\
\text { Motivation }\end{array}$ & $\begin{array}{c}(\mathrm{n}=626) \\
13.2(8.7)\end{array}$ & $\begin{array}{l}\mathrm{n}=470 \\
9.9+(7.6)\end{array}$ & $\begin{array}{c}(\mathrm{n}=494 \\
12.0 \ddagger(8.0)\end{array}$ & $\begin{array}{l}(\mathrm{n}=454) \\
9.6 \|(6.9)\end{array}$ \\
\hline $\begin{array}{l}\text { Definitely wants to quit (\%) } \\
\text { Self-efficacy }\end{array}$ & 23 & $35 \dagger$ & $44 \ddagger$ & $44 \rrbracket$ \\
\hline $\begin{array}{l}\text { Thinks quitting very } \\
\text { difficult }(\%)\end{array}$ & 25 & $34 \dagger$ & 26 & 32 \\
\hline $\begin{array}{l}\text { Ever tried to quit (\%) } \\
\text { Mean number quit attempts (SD) }\end{array}$ & $\begin{array}{l}49 \\
1.1(1.4)\end{array}$ & $\begin{array}{l}64 \dagger \\
1.3 \dagger(1.4)\end{array}$ & $\begin{array}{l}77 \ddagger \\
2.5 \ddagger(6.6)\end{array}$ & $\begin{array}{l}79 \S \\
2.3 \S(3.4)\end{array}$ \\
\hline
\end{tabular}

* Recent quitters are defined as former smokers who reported quitting during the two years before the interview.

$\dagger \mathrm{p}<0.05$, comparison of pretest HOU and pretest SCC.

$\ddagger \mathrm{p}<0.05$, comparison of pretest HOU and post-test HOU.

$\mathrm{p}<0.05$, comparison of pretest $\mathrm{HOU}$ and post-test HOU.
$\mathrm{p}<0.05$, comparison of pretest SCC and post-test SCC.

$\mathrm{p}<0.05$, comparison of pretest SCC and post-test SCC.
$\mathrm{p}<0.05$, comparison of post-test HOU and post-test SCC

Table 3 Multiple logistic regression analysis of current non-smoking status $(n=5250)$

\begin{tabular}{|c|c|c|c|}
\hline Characteristic & Variable & $\begin{array}{c}\text { Adjusted } \\
\text { odds } \\
\text { ratio }\end{array}$ & $\begin{array}{c}95 \% \\
\text { Confidence } \\
\text { interval }\end{array}$ \\
\hline \multirow[t]{2}{*}{ Site } & Houston & 1.0 & Referent \\
\hline & Santa Clara & 1.2 & $1.0,1.4$ \\
\hline \multirow[t]{2}{*}{ Time } & Pretest & 1.0 & Referent \\
\hline & Post-test & 0.9 & $0.8,1.1$ \\
\hline \multirow[t]{2}{*}{ Intervention term (site $\times$ time) } & $\begin{array}{l}\text { Pre-Santa Clara/pre-post } \\
\text { Houston }\end{array}$ & 1.0 & Referent \\
\hline & Post-Santa Clara & 1.2 & $0.9,1.5$ \\
\hline \multirow[t]{4}{*}{ Age (years) } & $18-24$ & 2.4 & $1.9,3.1$ \\
\hline & $25-44$ & 1.0 & Referent \\
\hline & $45-64$ & 1.8 & $1.5,2.1$ \\
\hline & $\geqslant 65$ & 3.4 & $2.4,4.7$ \\
\hline \multirow[t]{2}{*}{ Education } & $<$ College graduate & 1.0 & Referent \\
\hline & $\geqslant$ College graduate & 1.5 & $1.3,1.8$ \\
\hline \multirow{3}{*}{ English language proficiency } & None/fair/poor & 1.0 & Referent \\
\hline & Good & 1.3 & $1.1,1.5$ \\
\hline & Fluent & 2.0 & $1.5,2.6$ \\
\hline \multirow[t]{3}{*}{ Immigration } & Before 1977 & 1.8 & $1.5,2.2$ \\
\hline & $1978-84$ & 1.2 & $1.0,1.4$ \\
\hline & After 1984 & 1.0 & Referent \\
\hline \multirow[t]{2}{*}{ Employment } & Employment/student/ & 1.0 & Referent \\
\hline & $\begin{array}{l}\text { disabled/retired } \\
\text { Unemployment }\end{array}$ & 0.9 & $0.7,1.1$ \\
\hline \multirow{2}{*}{ Income } & Below poverty level & 1.0 & Referent \\
\hline & Above poverty level & 1.0 & $0.8,1.2$ \\
\hline
\end{tabular}

quit, more likely to report ever trying to quit and had made more attempts to quit, despite lower levels of perceived quitting self-efficacy than smokers in Houston. At post-test these differences had disappeared, however, and there were significant increases in motivation to quit and in reports of quit attempts in both communities.

Significant changes in social norms occurred between pretest and post-test in both communities. As Table 2 shows, the proportion of respondents reporting that a household member smoked declined, whereas the proportion reporting that no friends smoked rose. The proportion of respondents indicating that all or most of their friends smoked remained stable in Santa Clara County but increased in Houston. In addition, the percentage of neversmokers or former smokers advising family or friends to quit smoking increased between pretest and post-test. The rate in Santa Clara County increased from $51 \%$ to $62 \%$ (p < $0.05)$ whereas the rate in Houston increased from $34 \%$ to $66 \%(p<0.05)$. Similarly, the percentage of current or former smokers being advised to quit smoking by family or friends increased between pretest and post-test. The rate in Santa Clara County increased from $53 \%$ to $63 \%(p<0.05)$ whereas the rate in Houston increased from $51 \%$ to $62 \%$ (p < 0.05).

Finally, at post-test, respondents in both communities were more likely to have ever been advised by a physician to quit smoking. The rate in Santa Clara County increased from $28 \%$ to $51 \%(\mathrm{p}<0.05)$ whereas the rate in Houston increased from $12 \%$ to $39 \%$ (p < 0.05).

REGRESSION RESULTS

As Table 3 shows, the bivariate difference in smoking prevalence between the two communities did not persist after we controlled for differences in sociodemographic characteristics. The adjusted odds ratio (OR) for the intervention term was $1.1(95 \% \mathrm{CI}=0.9$ to 1.4), indicating that the intervention did not 


\section{Anh không} muốn bạn anh bị ung thu, tại sao anh mời bạn anh hút thuốc?

Sưc Khóe Là Vàng!

Vietnamese Community Health Promotion Project

U.C.-San Francisco

(415) 476-1202

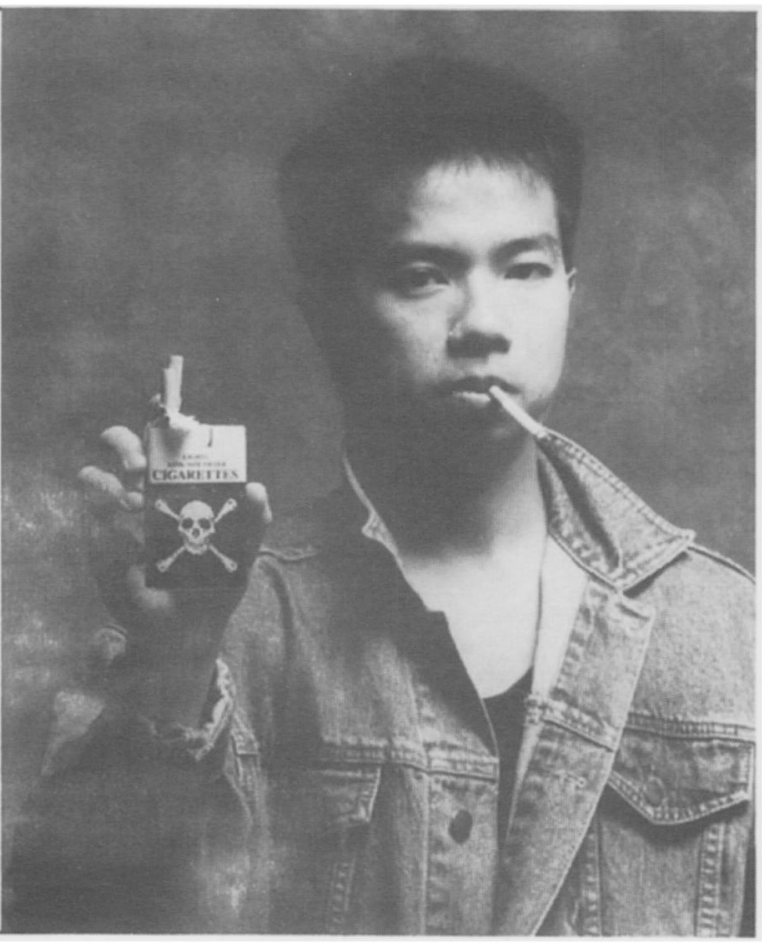

Figure 2 Sample Vietnamese newspaper anti-smoking advertisement based on billboards. "You wouldn't want your friend to get cancer, why do you offer him a cigarette?"

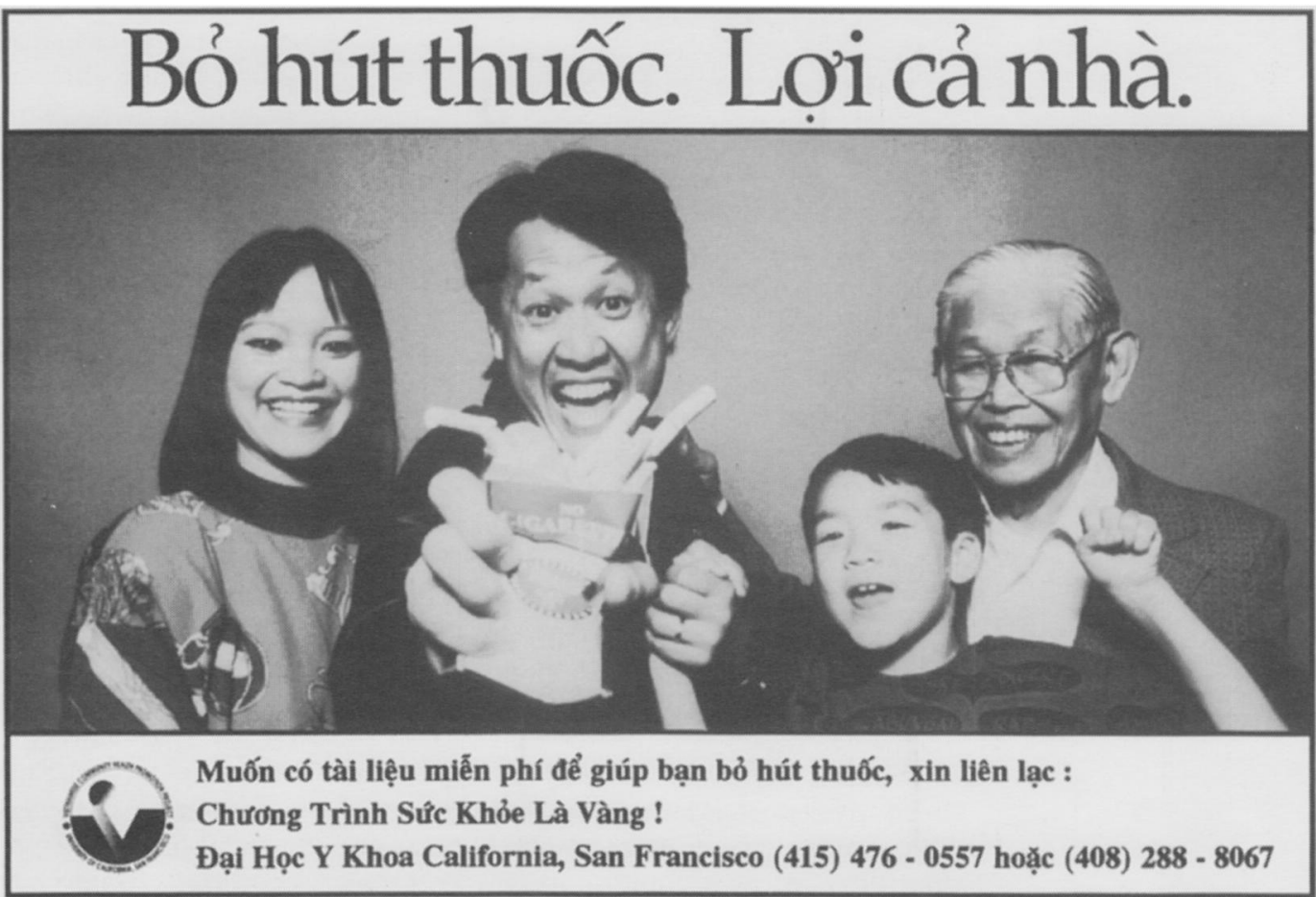

Figure 3 Sample Vietnamese newspaper anti-smoking advertisement based on billboards. "Quit smoking. The whole family benefits. To obtain free health education materials to help you quit smoking, please contact the Health Is Gold!' Project..."

measurably reduce smoking prevalence. Age 65 or over was the strongest predictor of current non-smoking status. Age 18-24, immigration before 1977, college graduation, and fluent proficiency in the English language were also significant predictors of non-smoking status. Employment and income were not significant predictors.

In the multiple logistic regression analysis for recent quitting status, the adjusted OR for the intervention term was $1.1(95 \% \mathrm{CI}=0.7$ to 1.7 ), indicating that the intervention did not 


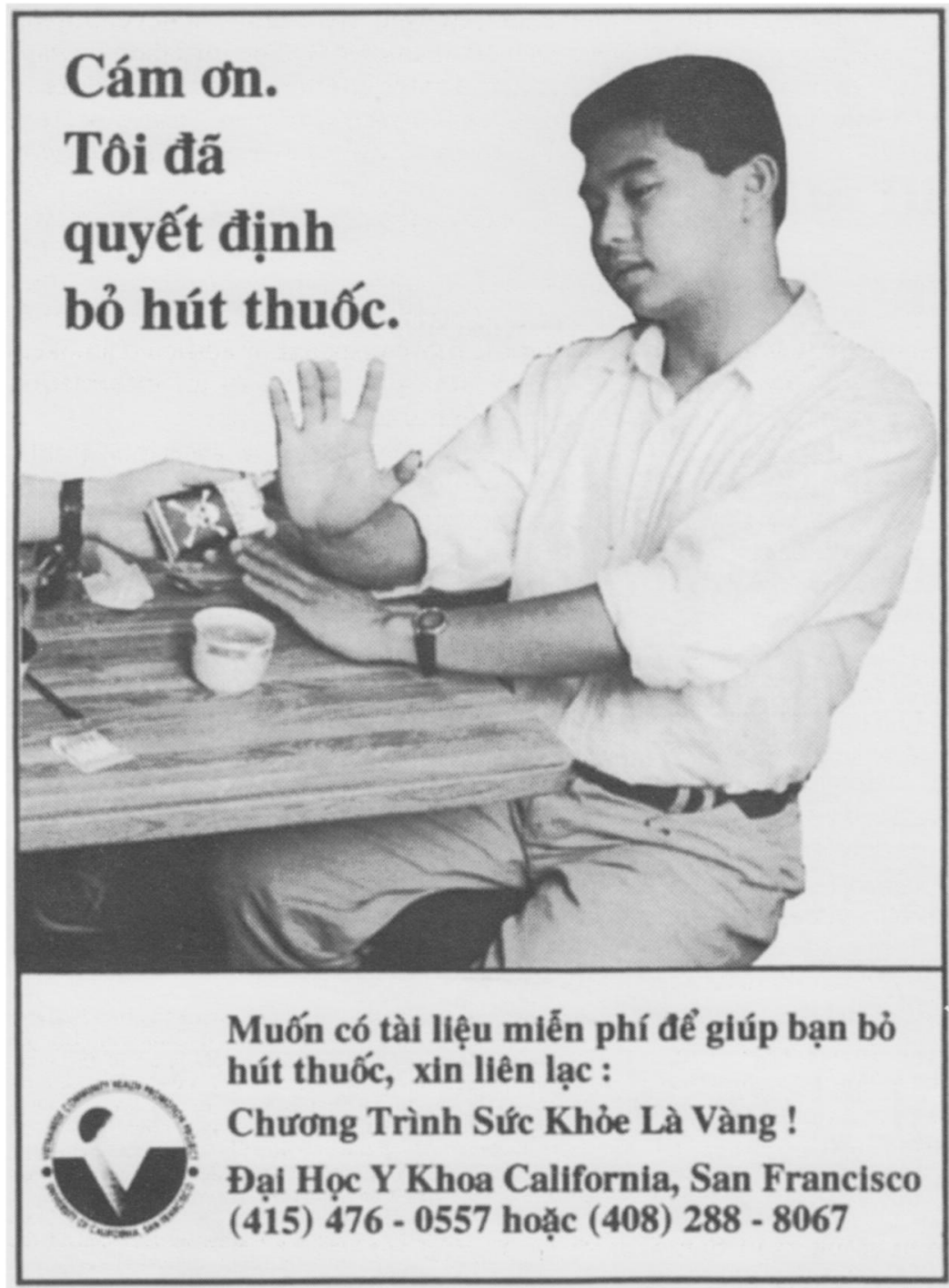

Figure 4 Sample Vietnamese newspaper anti-smoking advertisement based on billboards. "No thanks. I've decided to quit smoking. To obtain free health education materials..."
The data, however, do indicate some encouraging trends. In both communities, at post-test, more smokers were motivated to quit, had ever made an attempt to quit and had made more quit attempts than at pretest. Furthermore, the data show that more smokers reported being advised by their family, friends, and physicians to quit. Finally, although the mean number of cigarettes smoked per day remained constant in both communities, the number was lower among Vietnamese men than among white men. ${ }^{23,24}$

Predictors for smoking among Vietnamese men differ from those for the general population. Unemployment and low income did not predict smoking as they do in the general population. Consistent with the general population, however, lower educational level did predict smoking. ${ }^{25}$ In addition, lack of proficiency in the English language and recency of immigration were important predictors of smoking. These predictors are consistent with results of our earlier research and suggest that smoking rates among Vietnamese males may decline as they conform to the normative expectations of the social mainstream in which smoking prevalence is lower. ${ }^{4.6 .13}$

We recognise several important limitations to this study. Firstly, a cohort design may have provided a more sensitive test of the effect of this intervention than the independent crosssectional sample design used here. For example, other investigators evaluating a community-wide intervention aimed at smoking cessation have detected differences using a cohort sample, whereas no differences were found using cross-sectional samples. ${ }^{26} \mathrm{Sec}-$ ondly, the sample size based on the a priori power calculation permitted detection of a $5 \%$ or greater reduction in smoking prevalence, and thus we would be unable to detect a smaller change. Thirdly, we interviewed only respondents in households with listed telephones, which may have introduced a sampling bias. The relatively low population density of Vietnamese precluded the use of random-digit dialling techniques with any efficiency. Finally, the findings from this study cannot be generalised to Vietnamese elsewhere in the US.

The intervention reported here was a medialed information and education campaign, especially tailored to the Vietnamese community, set in the context of important state-wide tobacco control policy initiatives, including a recent increase in cigarette excise tax and a set of new ordinances restricting smoking. Such conditions should be optimal for the reduction of smoking in a community. ${ }^{23.27}$ Why, therefore, did the smoking prevalence not decline in the intervention community? We offer several possible explanations.

Firstly, a number of characteristics of the Vietnamese population may make smoking cessation a greater challenge for Vietnamese men, than for men in the general population. Among Vietnamese men, there is still considerable acceptance of smoking. In this study, for example, Vietnamese men reported that smoking was widespread in their social networks. In addition, smoking cessation may be vention, smoking prevalence remained alarmingly high among Vietnamese men with no significant increase in quitting. 
overshadowed by other issues such as reuniting families, finding employment, learning a new language, and adapting to a new culture. Because of their limited proficiency in the English language and recent arrival in the US, Vietnamese have not been exposed to the antitobacco messages Americans have been receiving for 30 years. Furthermore, the rate of quitting smoking is lower in groups with limited education. ${ }^{23,28,29}$ It may be that Vietnamese men, who have relatively low levels of education, will quit at slower rates than others.

Secondly, countervailing forces may be keeping smoking prevalence rates up. For example, the levelling off of the US smoking prevalence rate may be related in part to the steady growth in market share of discount cigarettes $^{30}$ and to the recent $10.4 \%$ annual increase in domestic expenditures for cigarette advertising and promotions. ${ }^{31}$ Asian Americans in California have been particularly targeted by tobacco advertisers. ${ }^{32}$ For example, recent studies have shown that the proportion of all billboards devoted to cigarette advertising in Asian neighbourhoods exceeds that found in white neighbourhoods by a factor of four in San Francisco and by a factor of 17 in Los Angeles (Bader and Houseman, unpublished data, 1993 and ${ }^{33}$ ). In San Francisco, investigators reported a higher density of cigarette advertising in Asian neighbourhoods (0.67 per block) compared with white neighbourhoods ( 0.15 per block). Such factors may have caused non-smokers to start smoking and discouraged smokers from quitting, thereby neutralising potential effects of the intervention. Indeed, analysis of our post-test data shows that $4.4 \%$ of current smokers in Santa Clara County and $5.3 \%$ of current smokers in Houston reported starting to smoke between 1990 and 1992.

Thirdly, a two-year intervention period may not be enough time to produce a measurable decline in smoking prevalence. Published studies have reported varying degrees of success with community-based anti-smoking intervention programmes. ${ }^{34-40}$ Several antismoking campaigns led by the mass media have required 3-10 years to show successful results. ${ }^{26,41,42}$ In a review of media-based interventions, Flay noted that effects increase with reach, frequency, and duration of exposures. ${ }^{44}$ Although the data in figure 1 indicate that the media intervention achieved a broad reach in the community, the frequency and duration of media exposure may not have been sufficient.

Several studies using different survey methodologies and in different locales in California have examined smoking prevalence rates among Vietnamese adult males during the past decade. In face-to-face interviews, Rumbaut found a rate of $65 \%$ in San Diego in $1984 .{ }^{45}$ We found rates of $56 \%$ in San Francisco and Oakland in 1987 in face-to-face interviews, ${ }^{6} 45 \%$ in San Francisco and Los Angeles in 1989 using telephone interviews, ${ }^{13}$ and $35 \%$ in a telephone survey of a California state-wide sample in $1991 .^{3,4}$ The apparent trend is downward between 1984 and 1991 but the data reported here show a levelling off between 1990 and 1992. The initial downward trend may represent the combined effects of quitting related to acculturation, quitting attributable to the 1989 increase in the cigarette excise tax, and quitting related to the pilot anti-tobacco activities we conducted from 1989 to 1990 . The apparent plateau in the smoking rate between 1990 and 1992 may indicate that those most likely to quit had already done so, leaving the more resistant or addicted smokers who were less susceptible to an information and education campaign. ${ }^{46}$

Smoking continues to be a serious public health problem for Vietnamese. Vietnamese men smoke at a rate of one and a half times that of men in the general population. Tailored intervention programmes are needed to target Vietnamese at high risk, particularly recent immigrants. Such interventions must be sustained for longer time periods. Further increases in tobacco excise taxes and more stringent smoking regulations are also needed to help counteract the effects of cigarette advertising. In combination, these efforts may bolster changes in social norms already under way and help smoking rates to decrease further as Vietnamese adjust to life in the US.

This research was supported by funds provided by the Cigarette and Tobacco Surtax Fund of the State of California through the Tobacco-Related Disease Research Program of the University of California, Grant Number RT 0048. The authors versity of California, Grant Number RT 0048 . The authors
wish to acknowledge the help and support of Charles L Gruder, wish to acknowledge the help and support of Charles L Gruder,
Frank Cappell, and Walter Price of the Tobacco-Related Frank Cappell, and Walter Price of the Tobacco-Related
Disease Research Program. Copies of Vietnamese language anti-smoking materials developed by the research team are available from the Tobacco Education Clearinghouse of California, PO Box 1830, Santa Cruz, CA 95061-1830, USA $(T e l+18002589090)$, from the California Division of the American Cancer Society, or from the investigators.

1 US Bureau of the Census. Press release No CB91-215; 1991

2 Bouvier LF, Agresta AJ. The future Asian population of the United States. In: Fawcett JT, Carino BV, eds. Pacific bridges: the new immigration from Asia and the Pacific Islands. Staten Island, New York: Center for Migration Studies, 1987.

3 US Centers for Disease Control. Behavioral risk factor survey of Vietnamese in California-1991. MMWR $1992 ; 41: 69-72$.

4 US Centers for Disease Control.Cigarette smoking among Chinese, Vietnamese, and Hispanics - California, 19891991. MMWR 1992; 41: 362-7.

5 US National Center for Health Statistics. Health, United States, 1992. Hyattsville, Maryland: Public Health Service, 1993.

6 Jenkins CNH, McPhee SJ, Bird JA, Bonilla N-T. Cancer risks and prevention practices among Vietnamese refugees. West f Med 1990; 153 : 34-9.

7 Pierce JP, Burns DM, Berry C et al. Reducing tobacco consumption in California: Proposition 99 seems to work. FAMA 1991; 265: 1257-8.

8 Popham WJ, Potter LD, Bal DG, Johnson MD, Duerr JM, Quinn V. Do anti-smoking media campaigns help smokers quit? Public Health Rep 1993; 108: 510-13.

9 Marine C. First billboard in Vietnamese. San Francisco Examiner 1990 Jan 5; A-9.

10 Johnson S. Ad barrage to get tough on the puff. San fose Mercury News 1990 Feb 5; 1A.

11 Parmley S. What are friends for? Billboard's blunt message gets the word out to Vietnamese community. Los Angeles Times 1990 Feb 11; A3.

12 Pertschuk M, Shopland DR. Major local smoking ordinances in the United States: a detailed matrix of the provisions of workplace, restaurant, and public places smoking ordinances. Rockville, Maryland: US Department of Health and Human Services, Public Health Service, 1989. (NIH Publication No 90-479.)

13 Jenkins CNH, McPhee SJ, Bonilla N-T, Nam TV, Chen A. Cigarette smoking among Vietnamese immigrants in California. Am $\mathcal{F}$ Health Promotion 1995; 9: 254-6. 
14 Cook TD, Campbell DT. Quasi-experimentation: design and analysis issues for field studies. Chicago: Rand McNally College, 1979 ; 115-17.

15 Kish L. Survey sampling. New York: Wiley, 1965

16 Anonymous. Annual update of the federal poverty income guidelines. Federal Register 1990 Feb $16 ; 5664-6$.

17 Anonymous. Income eligibility guidelines, July 1, 1992June 30, 1993. Federal Register 1992 Mar 25; 57(58): 10331 .

18 SAS Institute, Inc. SAS technical report P-200. SAS/ STAT software, CALIS and LOGISTIC procedures, release 6.04, Cary, North Carolina: SAS Institute, 1990

19 Centers of Disease Control. Cigarette smoking among adults - United States, 1990. MMWR 1992; 41: 354-5, 361-2.

20 Centers of Disease Control. Cigarette smoking among adults - United States, 1991. MMWR 1993; 42: 230-3

22 American Cancer Society. 1994 California cancer facts and figures. Oakland, California: California Division, American Cancer Society, 1993.

23 US Department of Health and Human Services. Reducing the health consequences of smoking : 25 years of progress. A report of the Surgeon General, 1989. Rockville, Maryland: Public Health Service, Centers for Disease Control, Office on Smoking and Health, 1989. (DHHS Publication No (CDC) 89-8411.)

24 Vander Martin R, Cummings SR, Coates TJ. Ethnicity and smoking: differences in white, black, Hispanic, and 6:194-9.

25 Novotny TE, Warner KE, Kendrick JS, Remington PL. Smoking by blacks and whites: socioeconomic an demographic differences. Am $\mathcal{F}$ Public Health 1988; 78 : 1187-9.

26 Farquhar JW, Fortmann SP, Flora JA, et al. Effects of communitywide education oncardiovascular disease risk factors, the Stanford five-city project. $¥ A M A 1990 ; 264$ : factors,

27 Stanley $\mathrm{K}$ Control of tobacco production and use. In: Jamison DT, Mosley WH, Measham AR, Bobadilla JL, eds. Disease control priorities in developing countries, New York, New York: World Bank, Oxford University Press, 1993; 703-723.

28 Pierce JP, Fiore MC, Novotny TE, Hatzandreu EJ, Davis RM. Trends in cigarette smoking in the United States: educational differences are increasing. $\mathcal{F} A M A 1989 ; 261$ : 56-60.

29 Macaskill P, Pierce JP, Simpson JM, Lyle DM. Mass media-led antismoking campaign can remove the education gap in quitting behavior. Am $\mathcal{F}$ Public Health 1992; 82: $96-8$.

30 Maxwell JC, Jr. The Maxwell consumer report: third quarter 1992 sales estimates for the cigarette industry. Richmond, Virginia: Butcher and Singer, 1992 Oct 20 (Publication No WFBS-6824.)
31 US Federal Trade Commission. Federal Trade Commission report to Congress for 1990: pursuant to the Federal Cigarette Labeling and Advertising Act. Washington, DC: US Federal Trade Commission, 1992.

32 McLaughlin K. Tobacco foes decry 'genocide of a people': Groups cite poll on ads aimed at Asian-Americans. San fose Mercury News 1993 Jun 5; 1 A.

33 Elder JP, Edwards C, Conway TL. Independent evaluation of Proposition-99 funded efforts to prevent and control tobacco use in California. Draft Annual Report, submitted to the California Department of Health Services, Oct to the
1993.

34 Gruder CL, Warnecke RB, Jason LA, Flay BR, Peterson P. A televised, self-help, cigarette smoking cessation intervention. Addict Behav 1990; 15: 505-16.

35 Lando HA, Loken B, Howard-Pitney B, Pechacek T. Community impact of a localized smoking cessation contest. Am f Public Health 1990; 80: 601-3.

36 Lefebvre RC, Cobb GD, Goreczny AJ, Carleton RA. Efficacy of an incentive-based community smoking cessation program. Addict Behav 1990; 15: 403-11.

37 Gritz ER, Berman BA, Bastani R, Wu M. A randomized trial of a self-help smoking cessation intervention in a nonvolunteer female population: testing the limits of the public health model. Health Psychol 1992; 11: 280-9.

38 Osler M, Jespersen NB. The effect of a community-based cardiovascular disease prevention project in a Danish municipality. Danish Med Bull 1993; 40: 485-9.

39 Leinweber CD, Macdonald JM, Campbell HS. Community smoking cessation contests: an effective public health strategy. Can $\mathcal{F}$ Public Health 1994; 85: 95-8.

40 Marin BV, Perez-Stable EJ, Marin G, Hauck WW. Effects of a community intervention to change smoking behavio among Hispanics. Am $\mathcal{f}$ Health Promotion 1994; 10 340-7.

41 Salonen JT, Puska P, Kottke TE, Tuomilehto J. Changes in smoking, serum cholesterol, and blood pressure levels during a community-based cardiovascular disease prevention program - the North Karelia Project. $A m f$ vention program - the North
Epidemiol 1981; 114: 81-94.

42 Fortmann, 1993

43 Flay BR. Mass media and smoking cessation: a critical review. Am f Public Health 1987; 77: 153-60.

44 Rumbaut RG. Portrait, patterns and predictors of the refugee adaptation process: results and reflections from the IHARP panel study. In Haines DW, ed. Refugees as immigrants: Cambodians, Laotians, and Vietnamese in America. Totowa, New Jersey: Rowman \& Littlefield, 1989.

45 US Department of Health and Human Services. The health consequences of smoking : cardiovascular disease. A report of
the Surgeon General, 1983. Rochville, Maryland: Public Health Service, Office on Smoking and Health, 1983. (DHHS Publication No (PHS) 84-50204.) 